\title{
Daily vancomycin dose requirements as a continuous infusion in obese versus non-obese SICU patients
}

\author{
Hsin Lin ${ }^{1 *}$, Daniel Dante Yeh ${ }^{2}$ and Alexander R. Levine ${ }^{3}$
}

\begin{abstract}
Background: Limited data are available assessing vancomycin concentrations in obese critically ill patients. Currently, there are no studies evaluating dosing requirements in this population who receive vancomycin administered as a continuous infusion (Cl). The aim of this study was to assess whether there was a difference in the weight-based maintenance dose required to reach a therapeutic vancomycin concentration at 24 hours when given as a $\mathrm{Cl}$ in obese versus non-obese critically ill patients.

Methods: A retrospective cohort study of adult obese patients admitted to the SICU between 2013 and 2015 receiving a vancomycin $\mathrm{Cl}(\mathrm{CIV})$, and with 24-hour serum measurements were included. Obese patients (body mass index $(\mathrm{BMI}) \geq 35 \mathrm{~kg} / \mathrm{m}^{2}$ ) were matched with non-obese patients $\left(\mathrm{BMl}<30 \mathrm{~kg} / \mathrm{m}^{2}\right.$ ) based on renal function, age and acute physiology and chronic health evaluation (APACHE)-II score at admission. All patients in this study received a loading dose of $25 \mathrm{mg} / \mathrm{kg}$ then a maintenance dose based on renal function according to the protocol. The study was approved by the Institutional Review Board. The primary outcome was the weight-based total daily maintenance dose required to achieve a vancomycin level of $20 \mathrm{mg} / \mathrm{L}$. The secondary endpoints included the achievement of a therapeutic level at 24 hours.
\end{abstract}

Results: Twenty-six matched pairs of patients met the inclusion criteria. Of these, 17 pairs had preserved renal function and 9 pairs required continuous venovenous hemofiltration. Mean BMI was $40.9 \mathrm{~kg} / \mathrm{m}^{2}$ in obese and $24.8 \mathrm{~kg} / \mathrm{m}^{2}$ in non-obese patients. To achieve a vancomycin concentration of $20 \mathrm{mg} / \mathrm{L}$, the weight-based daily maintenance dose in obese patients was $25.6 \mathrm{mg} / \mathrm{kg}$ versus $43.8 \mathrm{mg} / \mathrm{kg}$ in non-obese patients $(p<0.01)$. Therapeutic 24 -hour levels were achieved in $24 / 26$ obese versus $23 / 26$ no-obese patients ( $p=0.63$ ). Mean 24 -hour vancomycin level was $20.3 \pm 3.81 \mathrm{mcg} / \mathrm{ml}$ in obese compared to $20.03 \pm 3.79 \mathrm{mcg} / \mathrm{ml}$ in non-obese patients ( $p=0.77$ ). Mean daily maintenance doses required to achieve a level of $20 \mathrm{mcg} / \mathrm{ml}$ were $2961 \pm 1670 \mathrm{mg}$ in obese compared to $3189 \pm 1600.69 \mathrm{mg}$ in non-obese $(p=0.61)$.

Conclusions: The results of our study suggest that critically ill obese patients treated with CIV required a significantly lower maintenance dose per unit of body weight than non-obese patients to achieve the same target level.

Keywords: Vancomycin continuous infusion, Obesity, Pharmacokinetic and pharmacodynamic, Infectious disease

\section{Background}

The prevalence of obesity has more than doubled worldwide since 1980 and it is estimated that $60 \%$ of the world's population will be classified as overweight or obese by the year 2030 [1]. Given this trend, it is

\footnotetext{
* Correspondence: hlin13@partners.org

'Department of Pharmacy, Massachusetts General Hospital, 55 Fruit Street,

Boston, MA 02114, USA

Full list of author information is available at the end of the article
}

important to characterize the effect of obesity on drug disposition. Critically ill patients are at risk of alterations to pharmacokinetics due to having a larger volume of distribution and alteration in protein binding [2]. Several physiologic changes in obesity affect antimicrobial pharmacokinetics. For example, the volume of distribution in obese patients is greater due to increased lean body mass and adipose tissue [3]. Drug clearance may 
also be further enhanced due to increased kidney mass and filtration [4].

Optimizing antibiotic dosing is a priority in critically ill patients because inadequate systemic concentrations may lead to treatment failure and development of antimicrobial resistance [5]. It is imperative that the initial dosing regimens provide adequate pharmacodynamic exposure for the most likely pathogen. Vancomycin is the most common first-line option for treating methicillinresistant Staphylococcus aureus or other resistant Grampositive bacteria, such as coagulase-negative staphylococci and ampicillin-resistant enterococci in severe healthcare-associated infections.

Despite an increasing number of obese patients worldwide, there is little information on how to optimally dose vancomycin in these patients. Few studies have evaluated vancomycin concentrations in obese critically ill patients, and studies are limited by small patient groups and utilization of standard intermittent vancomycin dosing $[4,6-10]$. Currently, there are no studies evaluating dosing requirements in this population when receiving vancomycin continuous infusions (CIV). The aim of this study was to determine the weight-based dosing requirement of CIV necessary to reach the 24-hour target concentration in obese versus non-obese critically ill patients.

\section{Methods}

We reviewed all adult patients ( $\geq 18$ years old) who received CIV, either as monotherapy or combined with other antibiotics, in our multidisciplinary surgical ICU between January 2013 and January 2015. Patients were identified using the pharmacy informatics system. We included all adult patients who had a body mass index (BMI) $\geq 35 \mathrm{~kg} / \mathrm{m}^{2}$, and had measurement of serum vancomycin concentrations 24 hours after treatment. Patients who had previously received vancomycin within 48 hours prior to the start of the continuous infusion (CI) were excluded. The protocol was approved by the Partners Institutional Review Board, which waived the need for informed consent because of the retrospective nature of the study.

Demographic data (age, sex, total body weight (TBW), ideal body weight (IBW), adjusted body weight (ABW), height, BMI, creatinine clearance upon vancomycin initiation $(\mathrm{CrCL})$, severity of illness score (acute physiology and chronic health evaluation (APACHE) II) calculated at the time of ICU admission, and laboratory parameters were retrospectively collected for each patient in the study. ABW was calculated as follows:

$$
\mathrm{ABW}=0.4(\mathrm{TBW}-\mathrm{IBW})+\mathrm{IBW} .
$$

TBW was estimated and measured by the nurse using the patient's bed scale on the day of vancomycin therapy.
Other gathered data included use of continuous venovenous hemofiltration $(\mathrm{CVVH}), \mathrm{CVVH}$ hemofiltration rate, use of vasopressors or mechanical ventilation, vancomycin dose, and serum vancomycin concentration. Nephrotoxicity was defined as an increase in serum creatinine $(\mathrm{SCr})$ by $0.5 \mathrm{mg} / \mathrm{dL}$ or at least a $50 \%$ increase from baseline over two consecutive $\mathrm{SCr}$ values for patients not requiring $\mathrm{CVVH}$.

CI vancomycin clearance (CLvanc) was calculated using the following equation:

$$
\frac{\text { Dose }(\mathrm{mg} / \mathrm{hr})}{\text { Serum concentration }(\mathrm{mg} / \mathrm{L})}=\text { CLvanc }(\mathrm{L} / \mathrm{hr})
$$

Area under the concentration curve $24 \mathrm{hr}$ (AUC24) was calculated as follows:

$$
\text { serum vancomycin concentration }\left(\frac{\mathrm{mg}}{\mathrm{L}}\right) * 24 \mathrm{hr}
$$

Daily vancomycin dose $(\mathrm{mg})$ needed to obtain a target concentration of $20 \mathrm{mg} / \mathrm{L}$ while on CI:

$$
\text { target concentration } 20\left(\frac{\mathrm{mg}}{\mathrm{L}}\right) * \text { CLvanc }\left(\frac{\mathrm{L}}{\mathrm{hr}}\right) * 24 \mathrm{hr}
$$

The 24-hour urine creatinine clearance $(\mathrm{CrCL})$ was calculated using the following formula:

$$
\mathrm{CrCL}\left(\frac{\mathrm{ml}}{\mathrm{min}}\right)=\frac{(\text { Urine output, } \mathrm{ml}) *\left(\text { Urinary creatinine }, \frac{\mathrm{mg}}{\mathrm{dL}}\right)}{\left(\text { serum creatinine }, \frac{\mathrm{mg}}{\mathrm{dL}}\right) *(\text { Time of urine collection, minutes })}
$$

All CVVH treatments applied the CAR-505 filter with a polyethersulfone membrane with a $1.6 \mathrm{~m}^{2}$ membrane surface area in conjunction with the NxStage System One dialysis machine. Vancomycin concentration analysis utilized a Syva Emit 2000 vancomycin assay (Siemens Healthcare Diagnostics, Inc. Newark, DE, USA). The assay has an analytical range between 5.0 and $50.0 \mathrm{mcg} / \mathrm{ml}$, and the between-run coefficient of variation was $<10 \%$ throughout the analytical range.

\section{Vancomycin treatment and measurements}

In our surgical ICU, the use of CIV is at the discretion of the treating ICU physician and at a loading dose of $25-30 \mathrm{mg} / \mathrm{kg}$, followed by maintenance doses adjusted based on $\mathrm{CrCL}$ or $\mathrm{CVVH}$. Calculated $\mathrm{CrCL}$ was estimated using the Cockcroft-Gault (CG) equation using ABW. To account for a falsely elevated CrCL estimate in patients $>65$ years of age in whom low $\mathrm{SCr}$ values may indicate reduced muscle mass, $\mathrm{SCr}$ values $<0.8 \mathrm{mg} / \mathrm{dL}$ were adjusted up to $0.8 \mathrm{mg} / \mathrm{dL}$. CG CrCL was used in the dosing nomogram because 24-hour urine creatinine cannot provide immediate results and rapid administration of antibiotic is often essential. Of note, 24-hour urine creatinine is not performed daily in the study center, instead it is collected on the first day of CIV therapy. 
The daily maintenance dose starts at $2000 \mathrm{mg}$ for CG $\mathrm{CrCL}$ of $60 \mathrm{ml} /$ minute; increases in CG CrCL of $10 \mathrm{ml} /$ minute requires an increase in maintenance dose of $250 \mathrm{mg}$ vancomycin. The maximum maintenance dose is started at $4250 \mathrm{mg}$. For patients who receive concomitant $\mathrm{CVVH}$, the initial vancomycin dose is $1500 \mathrm{mg}$ daily.

Doses were not changed during the first 24 hours of therapy; afterwards, the daily regimen was adapted using a specific approach: if serum vancomycin concentration was $<15 \mathrm{mg} / \mathrm{L}$, an additional dose of 500 to $1000 \mathrm{mg}$ was given as a bolus followed by an increased total daily dose proportional to the goal serum concentration. If the concentration was $>25 \mathrm{mg} / \mathrm{L}$, the CIV was discontinued for 4 to 6 hours and resumed with the daily dose reduced proportionally. Serum vancomycin concentrations were determined every 24 hours until two serum concentrations were within target range $(15-25 \mathrm{mg} / \mathrm{L})$. If $\mathrm{CVVH}$ was stopped due to a clotted circuit, the CIV was stopped and the infusion resumes once CVVH was restarted.

\section{Matched controls}

Using an institutional database of all ICU patients who received CIV during the same period, obese ICU patients $\left(\mathrm{BMI}>35 \mathrm{~kg} / \mathrm{m}^{2}\right.$ ) were matched with non-obese ICU patients $\left(B M I<30 \mathrm{~kg} / \mathrm{m}^{2}\right.$ ) according to three criteria: (1) renal function (either the same 24-hour urine $\mathrm{CrCL}$ with a range of eligibility for matching of $25 \mathrm{ml} /$ minute, or if on CVVH, the same CVVH intensity with a range of eligibility for matching of $10 \mathrm{ml} / \mathrm{kg} /$ minute); (2) age (range of eligibility for matching of 15 years); and (3) APACHE II score at admission (range of eligibility for matching of 10).

\section{Endpoints}

The primary outcome was the weight-based daily maintenance dose requirement to achieve vancomycin concentration of $20 \mathrm{mg} / \mathrm{L}$ at 24 hours. Secondary outcomes were achievement of a therapeutic level by 24 hours, CLvanc/IBW, CLvanc/ABW, CLvanc/TBW, and AUC24. Therapeutic levels were defined as a range of 15 to $25 \mathrm{mg} / \mathrm{L}$ to achieve an adequate AUC [11, 12].

\section{Statistical analysis}

Distributions of quantitative outcomes were summarized by the mean with standard deviation and were compared using the Mann-Whitney $U$ test. Categorical outcomes were summarized by counts and proportions and compared using the Chi-square test (or the Fisher's exact test as appropriate). Linear regression was used to identify the correlation between CLvanc and CrCL. All analyses were performed using STATA Data Analysis and Statistical Software (version 13; StatCorp LP, College Station, TX, USA). A $p$ value $<0.05$ was considered statistically significant.

\section{Results}

Twenty-six matched pairs of patients met the inclusion criteria. Of these, 17 pairs of patients had preserved renal function and 9 pairs required CVVH. Baseline values of ABW, TBW, and percent over IBW and BMI were significantly different (Table 1). Mean BMI was $41 \mathrm{~kg} / \mathrm{m}^{2}$ in obese and $24.9 \mathrm{~kg} / \mathrm{m}^{2}$ in nonobese patients. In patients with preserved renal function $(n=34)$, mean 24-hour urine CrCL was $166 \mathrm{ml} /$ minute in obese patients versus $168 \mathrm{ml} / \mathrm{minute}$ in non-obese patients. In patients $(n=18)$ receiving CVVH, mean hemofiltration rates were $21.3 \mathrm{ml} / \mathrm{kg} / \mathrm{h}$ in obese patients versus $21.9 \mathrm{ml} / \mathrm{kg} / \mathrm{h}$ in non-obese

Table 1 Demographic data

\begin{tabular}{|c|c|c|c|}
\hline & $\begin{array}{l}\text { Obese patients } \\
(n=26)\end{array}$ & $\begin{array}{l}\text { Non obese } \\
\text { patients }(n=26)\end{array}$ & $\begin{array}{l}P \\
\text { value }\end{array}$ \\
\hline Age, years & $54.2(16.8)$ & $55.4(16.0)$ & 0.781 \\
\hline Male, $n$ & 18 & 21 & 0.337 \\
\hline TBW, kg & $117(23.3)$ & $75.2(13.3)$ & $<0.001$ \\
\hline ABW, kg & $87.7(13.7)$ & $71.0(11.1)$ & $<0.001$ \\
\hline IBW, kg & $67.9(13.1)$ & $68.5(10.5)$ & 0.88 \\
\hline Height, in & $67.6(4.63)$ & $68.5(3.38)$ & 0.393 \\
\hline Over IBW, \% & $1.77(0.43)$ & $1.1(0.112)$ & $<0.001$ \\
\hline $\mathrm{BMI}, \mathrm{kg} / \mathrm{m}^{2}$ & $41.0(8.12)$ & $24.9(3.16)$ & $<0.001$ \\
\hline APACHE $\|$ & $20.3(9.24)$ & $18.7(8.46)$ & 0.524 \\
\hline Hospital mortality, $n$ & 5 & 4 & 0.714 \\
\hline Mechanical ventilation, $n$ & 24 & 26 & 0.149 \\
\hline Use of vasopressors, $n$ & 15 & 20 & 0.139 \\
\hline $\mathrm{CWH}, n$ & 9 & 9 & 1 \\
\hline $\begin{array}{l}\text { Urine creatinine clearance } \\
(\mathrm{ml} / \mathrm{min}), n=17\end{array}$ & $166(62.7)$ & $168.1(59.1)$ & 0.92 \\
\hline CWH flow rate, $\mathrm{ml} / \mathrm{kg} / \mathrm{h}$ & $21.3(7.09)$ & $21.9(6.47)$ & 0.86 \\
\hline Duration of vancomycin, days & $6.88(3.02)$ & $6.5(3.06)$ & 0.415 \\
\hline $\begin{array}{l}\text { Time from ICU admission to } \\
\text { vancomycin initiation, days }\end{array}$ & $2.73(1.66)$ & $2.53(1.33)$ & 0.647 \\
\hline $\begin{array}{l}\text { Infection site } \\
\text { - Pneumonia } \\
\text { - Bacteremia } \\
\text { - SSTI } \\
\text { - Intraabdominal } \\
\text { - Unknown }\end{array}$ & $\begin{array}{l}16 \\
2 \\
2 \\
3 \\
3\end{array}$ & $\begin{array}{l}19 \\
0 \\
3 \\
2 \\
2\end{array}$ & $\begin{array}{l}0.375 \\
0.149 \\
0.638 \\
0.638 \\
0.638\end{array}$ \\
\hline $\begin{array}{l}\text { Microbiology results } \\
\text { - MRSA } \\
\text { - MSSA } \\
\text { - Enterococcus } \\
\text { - Streptococcus spp. } \\
\text { - CoN Staphylococcus } \\
\text { - Other }\end{array}$ & $\begin{array}{l}6 \\
2 \\
0 \\
2 \\
4 \\
12\end{array}$ & $\begin{array}{l}7 \\
3 \\
1 \\
3 \\
3 \\
9\end{array}$ & $\begin{array}{l}0.749 \\
0.638 \\
0.313 \\
0.638 \\
0.685 \\
0.397\end{array}$ \\
\hline
\end{tabular}

Results presented as mean (SD) unless stated otherwise. CVVH continuous venovenous hemofiltration, $T B W$ total body weight, $A B W$ adjust body weight, IBW ideal body weight, $B M I$ body mass index, APACHE Acute Physiology and Chronic Health Evaluation, SSTI skin soft tissue infection, MRSA methicillin-resistant Staphylococcus aureus, MSSA, methicillin-sensitive Staphylococcus aureus 
patients. No patients in either group with preserved renal function developed nephrotoxicity during vancomycin treatment.

\section{Endpoints}

For the primary endpoint, the weight-based daily maintenance dose required to achieve a therapeutic 24-hour serum concentration in obese patients was $24.8 \mathrm{mg} / \mathrm{kg}$ versus $41.9 \mathrm{mg} / \mathrm{kg}$ in non-obese patients $(p<0.001)$ (Table 2). There was no difference between groups in the mean 24-hour vancomycin serum concentration, mean daily maintenance doses, AUC24, or achievement of therapeutic concentration within 24 hours. Mean loading doses were $24.8 \mathrm{mg} / \mathrm{kg}$ versus $25.6 \mathrm{mg} / \mathrm{kg}$ in obese and non-obese patients, respectively, $p=0.135$.

In the subgroup of 18 patients who received $\mathrm{CVVH}$, there was no difference in the CLvanc/ABW or CLvanc/ IBW (Table 3). CLvanc/TBW was significantly lower in obese than non-obese patients, $p=0.04$. There was no correlation between CLvanc and TBW, IBW or ABW. There was strong positive correlation between CLvanc $(\mathrm{L} / \mathrm{h})$ and CVVH flow rate in obese patients $\left(r^{2}=0.93\right.$, $p<0.001)$ but poor correlation in non-obese patients $\left(r^{2}=0.2, p=0.226\right)$.

In the subgroup of 34 patients with preserved renal function, obese patients had significantly lower CLvanc/ CrCL than non-obese patients, $p=0.04$ (Table 4). Mean CLvanc in the obese group was $0.06 \mathrm{~L} / \mathrm{h}$ per $\mathrm{kg} \mathrm{TBW}$, whereas non-obese patients had a CL of $0.12 \mathrm{~L} / \mathrm{h}$ per $\mathrm{kg}$ TBW. There were no significant differences between obese and non-obese patients in CLvanc and CLvanc adjusted for IBW. There was no correlation between

Table 2 Vancomycin dose and treatment

\begin{tabular}{|c|c|c|c|}
\hline & $\begin{array}{l}\text { Obese } \\
(n=26)\end{array}$ & $\begin{array}{l}\text { Non obese } \\
(n=26)\end{array}$ & $P$ value \\
\hline Loading dose, mg & $2894(525)$ & $1923(345)$ & $<0.001$ \\
\hline Loading dose, mg/kg & $24.8(2.05)$ & $25.6(1.66)$ & 0.135 \\
\hline Maintenance dose, mg & $2885(1450)$ & 3039 (1313) & 0.69 \\
\hline Maintenance dose, mg/kg & $24.8(12.7)$ & $41.9(20)$ & $<0.001$ \\
\hline $\begin{array}{l}24 \text { hour serum concentration, } \\
\mathrm{mg} / \mathrm{L}\end{array}$ & $20.3(3.81)$ & $20.0(3.79)$ & 0.777 \\
\hline CLvanc, L/h & $6.16(3.47)$ & $6.64(3.33)$ & 0.617 \\
\hline $\begin{array}{l}\text { Dose needed to achieve } \\
\text { concentration of } 20 \mathrm{mg} / \mathrm{L}, \mathrm{mg}\end{array}$ & $2961(1670)$ & $3189(1601)$ & 0.617 \\
\hline $\begin{array}{l}\text { Dose per ABW needed to achieve } \\
\text { concentration of } 20 \mathrm{mg} / \mathrm{L}, \mathrm{mg} / \mathrm{kg}\end{array}$ & $25.57(14.8)$ & $43.8(23.5)$ & $<0.01$ \\
\hline AUC24 & 488. (91.5) & $480.9(91.04)$ & 0.777 \\
\hline $\begin{array}{l}\text { Achievement of therapeutic } \\
\text { concentration at } 24 \text { hours, } n\end{array}$ & 24 & 23 & 0.638 \\
\hline
\end{tabular}

Results are presented as mean (SD) or number. CLvanc continuous infusion vancomycin clearance, $A B W$ adjusted body weight, $A U C 24$ area under the concentration curve $24 \mathrm{~h}$
Table 3 Vancomycin dose and monitoring during CWH

\begin{tabular}{llll}
\hline & $\begin{array}{l}\text { Obese patients } \\
(n=9)\end{array}$ & $\begin{array}{l}\text { Non obese } \\
\text { patients }(n=9)\end{array}$ & $P$ value \\
\hline Goal concentration, $24 \mathrm{~h}, n$ & 9 & 9 & 1 \\
Serum concentration, 24 h, mg/L & $19.8(3.05)$ & $21.6(3.02)$ & 0.155 \\
$\begin{array}{l}\text { Dose needed to achieve } \\
\text { concentration of } 20 \mathrm{mg} / \mathrm{L}, \mathrm{mg}\end{array}$ & $1426(418)$ & $1383(282)$ & 0.802 \\
$\begin{array}{l}\text { Dose needed to achieve } \\
\text { concentration of } 20 \mathrm{mg} / \mathrm{L}, \mathrm{mg} / \mathrm{kg}\end{array}$ & $13.8(5.09)$ & $19.9(6.7)$ & 0.004 \\
Loading dose, mg & $2722(441)$ & $1833(280)$ & $<0.001$ \\
Loading dose, mg/kg & $25.3(0.774)$ & $25.4(1.49)$ & 0.847 \\
Maintenance dose, mg & $1389(397)$ & $1500(375)$ & 0.550 \\
Maintenance dose, mg/kg & $13.3(4.73)$ & $21.7(8.33)$ & 0.01 \\
AUC24 & $474(73.2)$ & $517(48.6)$ & 0.15 \\
CLvanc, L/h & $2.97(0.87)$ & $2.88(0.60)$ & 0.802 \\
CLvanc/ABW, L/h/kg & $0.04(0.01)$ & $0.04(0.01)$ & 0.34 \\
CLvanc/IBW, L/h/kg & $0.02(0.02)$ & $0.05(0.01)$ & 0.879 \\
CLvanc/TBW, L/h/kg & $0.03(0.01)$ & $0.04(0.01)$ & 0.044 \\
\hline
\end{tabular}

Results are presented as mean (SD) unless stated otherwise. $\mathrm{CVVH}$ continuous venovenous hemofiltration, AUC24 area under the concentration curve $24 \mathrm{~h}$, CLvanc continuous infusion vancomycin $\mathrm{Cl}, A B W$ adjusted body weight, IBW ideal body weight, $T B W$ total body weight

CLvanc and TBW in any patients as shown in Fig. 1a and $b$. There was good correlation between vancomycin $\mathrm{CL}$ and $\mathrm{CrCL}$ in obese patients $\left(r^{2}=0.87 p<0.001\right)$ and non-obese patients $\left(r^{2}=0.661, p<0.001\right)$ as shown in Fig. 2a and $b$.

Table 4 Vancomycin dosing and monitoring in patients with preserved renal function

\begin{tabular}{|c|c|c|c|}
\hline & $\begin{array}{l}\text { Obese patients } \\
(n=17)\end{array}$ & $\begin{array}{l}\text { Non-obese } \\
\text { patients }(n=17)\end{array}$ & $P$ value \\
\hline Goal concentration, 24 h, $n$ & 15 & 14 & 0.628 \\
\hline Serum concentration, 24 h, mg/L & $20.6(4.21)$ & $19.6(4.41)$ & 0.494 \\
\hline $\begin{array}{l}\text { Dose needed to achieve } \\
\text { concentration of } 20 \mathrm{mg} / \mathrm{L}, \mathrm{mg}\end{array}$ & $3774(1498)$ & $4141(1087)$ & 0.420 \\
\hline $\begin{array}{l}\text { Dose needed to achieve } \\
\text { concentration of } 20 \mathrm{mg} / \mathrm{L}, \mathrm{mg} / \mathrm{kg}\end{array}$ & $31.8(14.5)$ & $56.9(17.9)$ & $<0.001$ \\
\hline Loading dose, mg & $2985(555)$ & $1941(370)$ & $<0.001$ \\
\hline Loading dose, mg/kg & $24.6(2.47)$ & $25.9(1.88)$ & 0.09 \\
\hline Maintenance dose, mg & $3676(1131)$ & $3882(674)$ & 0.523 \\
\hline Maintenance dose, mg/kg & $30.8(11.3)$ & $53.4(13.7)$ & $<0.001$ \\
\hline $\mathrm{AUC24}$ & $496(101)$ & $471(106)$ & 0.494 \\
\hline CLvanc, L/h & $7.86(3.11)$ & $8.62(2.26)$ & 0.420 \\
\hline Clvanc/CrCL & $0.79(0.11)$ & $0.91(0.21)$ & 0.049 \\
\hline CLvanc/ABW, L/h/kg & $0.09(0.04)$ & $0.12(0.04)$ & 0.0074 \\
\hline CLvanc/IBW, L/h/kg & $0.12(0.05)$ & $0.12(0.04)$ & 0.404 \\
\hline CLvanc/TBW, L/h/kg & $0.06(0.03)$ & $0.12(0.04)$ & 0.0001 \\
\hline
\end{tabular}

Results are presented as mean (SD) unless stated otherwise. AUC24 area under the concentration curve $24 \mathrm{~h}$, CLvanc continuous infusion vancomycin clearance, $C r C L$ creatinine clearance, $A B W$ adjusted body weight, IBW ideal body weight, $T B W$ total body weight 


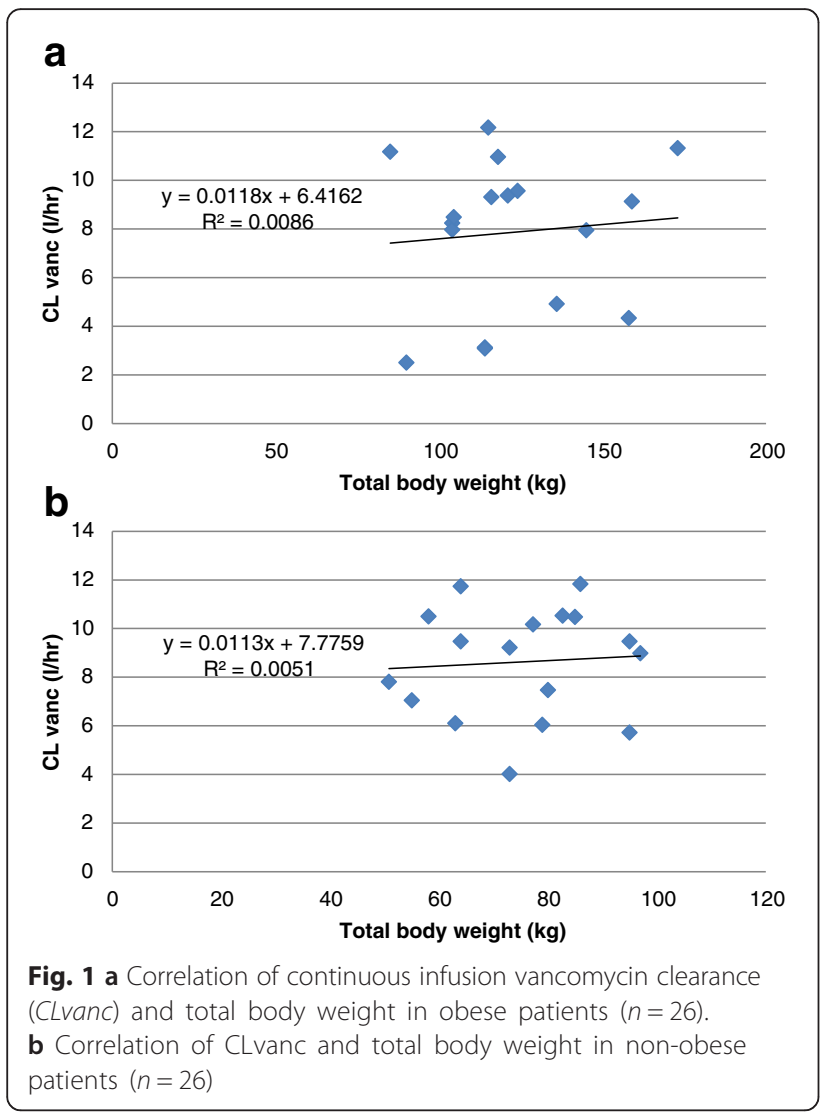

\section{Discussion}

To our knowledge, this is the first study to evaluate the dosing requirements of CIV in obese critically ill patients compared to a non-obese cohort. Our study has several key findings. First, the daily weight-based dose of CIV is significantly lower for obese patients than nonobese patients, thereby, reducing total drug exposure and potentially lowering their risk of kidney injury. Second, vancomycin clearance is similar in obese and non-obese patients and is poorly correlated with TBW. Finally, our results highlight that our CIV dosing protocol reliably achieved therapeutic concentrations in both obese and non-obese critically ill patients.

\section{Continuous vancomycin infusions reduce total daily drug exposure in obese patients}

CIV has been proposed as an alternative approach to optimize drug concentrations and efficacy in various critically ill patient populations. Although CI has not been proven to be superior to intermittent infusion for clinical effectiveness, CI enhances the probability of achieving optimal drug exposure and lessens the renal toxicity potential associated with more aggressive dosing [13]. For example, Hanrahan et al. demonstrated that patients who received intermittent vancomycin infusions

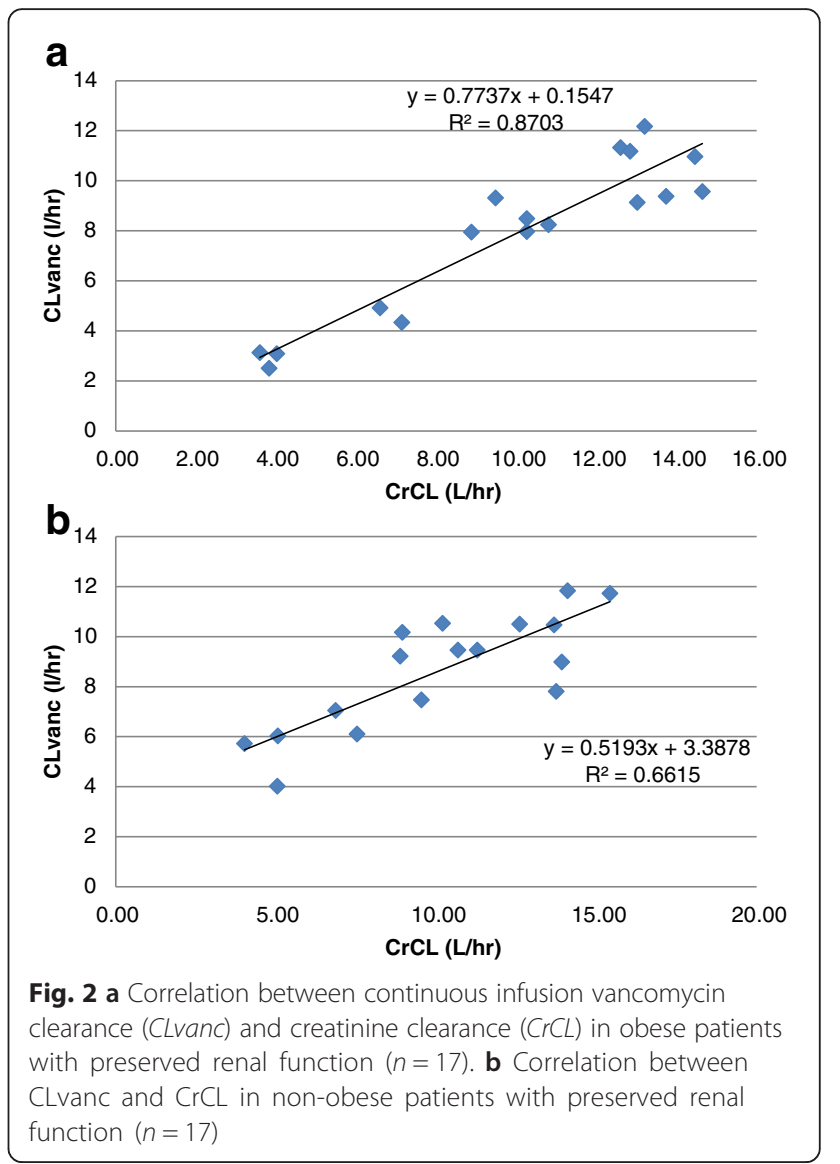

had 8.2 times greater odds of developing nephrotoxicity compared to CIV [14]. The risk of nephrotoxicity is further amplified in obese patients who traditionally receive significantly higher doses.

\section{Vancomycin clearance in obese patients is similar in non-obese patients and is not significantly associated with TBW}

Previous studies have identified greater CLvanc in obese patients with normal serum creatinine $[8,9,15]$. As obese patients have a larger volume of distribution $(\mathrm{Vd})$, they may have a higher $\mathrm{CrCL}$ and CLvanc. It has also been theorized that obese patients have a larger Vd due to greater quantity and size of nephrons and increased blood flow to the kidney $[16,17]$. Bauer et al. demonstrated that the extent of CLvanc increased significantly more than the increase in Vd in morbidly obese patients, suggesting a much shorter half-life [8]. However, in our study, we found no difference in CLvanc between obese and non-obese patients with preserved renal function. After adjusting CLvanc for various body weights, we observed no difference in CLvanc/IBW. This may imply that the potential increase in $\mathrm{Vd}$ in obese patients does not change proportionally to CLvanc. 
Consensus guidelines recommend using TBW to guide vancomycin dosing because data indicate that TBW predicts CLvanc in obese individuals [18]. Contrary to the previous findings we did not identify correlation between CLvanc and TBW in either group $[7,8]$. In our study the only variables statistically significantly associated with CLvanc were urine $\mathrm{CrCL}$ and $\mathrm{CVVH}$ hemofiltration rate. Both obese and non-obese patients with the same urine $\mathrm{CrCL}$ or $\mathrm{CVVH}$ hemofiltration rate required the same total daily vancomycin as a CIV to achieve the target concentration. Differences in our study population are a plausible explanation for these results: in previous studies, patients had TBW at least $90 \%$ over the IBW and had higher BMI compared to the patients in our study. The consequences of varying $\mathrm{Vd}$ in obesity can affect CLvanc and its relationship with TBW. Second, our study population represents critically ill patients who may have greater non-renal clearance compared to a non-ICU population. Therefore, when utilizing CIV in critically obese patients, our data suggest that clinicians should rely on 24-hour measured $\mathrm{CrCl}$ or the $\mathrm{CVVH}$ hemofiltration rate rather than TBW to assess CLvanc. Additional studies are needed to confirm these findings.

The strengths of our study include a well-matched cohort of obese and non-obese critically ill patients, use of a standardized CIV protocol, and incorporation of 24hour measured $\mathrm{CrCl}$ to estimate renal clearance of vancomycin. Cockcroft-Gault CrCL (CG CrCL) is one of the most commonly used methods for estimating renal function in the ICU. Most pharmacokinetics studies in critically ill patients rely on CG CrCL to estimate drug clearance and adjust drug dosages. However, the use of CG CrCL to estimate CrCL raises several concerns as it has been repeatedly shown to be inaccurate in the critical care setting, in particular, among patients with augmented renal clearance [19]. Only measured urine $\mathrm{CrCL}$ should be used to accurately guide drug dosing [20].

Our study is limited by its retrospective nature, as the data are subject to inherent biases and small sample size. Our patient population was representative of younger, obese critically ill surgical patients with high illness severity scores and mortality rates. Although our obese cohort was well-matched with a non-obese cohort, the subgroup of patients with preserved renal function had high mean creatinine clearance. Therefore, our findings may not be applicable to older, non-surgical ICU patients with impaired renal function. Additionally, the precision of the measurement of TBW in the study patients cannot be confirmed. Many confounders, such as the presence of a sheet, pillow, blanket and equipment on the patient's bed can falsely affect weight obtained from the bed scale and may not accurately reflect true TBW. Our study results rely on the precision of measured urine $\mathrm{CrCL}$ and it is not possible to rule out the potential for incomplete urine collection. We did not record data on clinical and microbiological response to vancomycin. Only half of our studied patients had a documented infection with Gram-positive bacteria; therefore, determining whether optimizing antibiotic concentrations with CIV leads to improved outcomes requires further study. Last, we did not assess the adequacy of our loading dose and the effects on vancomycin concentrations at 24 hours.

\section{Conclusion}

Utilization of CIV in obese patients consistently achieves target therapeutic serum concentrations and reduces the total weight-based daily exposure of vancomycin compared to non-obese patients. CIV clearance is similar in obese and non-obese patients and does not increase proportionally to $\mathrm{TBW}$.

\section{Abbreviations}

ABW, adjusted body weight; APACHE II, acute physiology and chronic health evaluation; AUC24, area under the concentration curve $24 \mathrm{~h}$; BMl, body mass index; $\mathrm{CG} \mathrm{CrCL}$, Cockcroft-Gault creatinine clearance; $\mathrm{Cl}$, continuous infusion; $\mathrm{CIV}$, vancomycin continuous infusions; CLvanc, Cl vancomycin clearance; $\mathrm{CrCL}$, creatinine clearance; $\mathrm{CWH}$, continuous venovenous hemofiltration; IBW, ideal body weight; MRSA, methicillin-resistant Staphylococcus aureus; MSSA, methicillin-sensitive Staphylococcus aureus; SCr, serum creatinine; SSTI, skin soft tissue infection; TBW, total body weight; Vd, volume of distribution

\section{Authors' contributions}

The study was designed collaboratively by HL, DY, and AL. Data collection was carried out by HL. Data analysis was performed by HL and DY. The manuscript was prepared by HL, DY, and AL. All authors read and approved the final manuscript.

\section{Competing interests}

The authors declare that they have no competing interests.

\section{Ethics approval and consent to participate}

The protocol was approved by the Partners Institutional Review Board, which waived the need for informed consent because of the retrospective nature of the study.

\section{Author details}

${ }^{1}$ Department of Pharmacy, Massachusetts General Hospital, 55 Fruit Street, Boston, MA 02114, USA. 'Departments of Surgery, Massachusetts General Hospital, 55 Fruit Street, Boston, MA 02114, USA. ${ }^{3}$ Department of Pharmacy Practice and Administration, University of Saint Joseph School of Pharmacy, 229 Trumbull St, Hartford, CT, USA

Received: 14 April 2016 Accepted: 27 May 2016

Published online: 01 July 2016

\section{References}

1. Hanley MJ, Abernethy DR, Greenblatt DJ. Effect of obesity on the pharmacokinetics of drugs in humans. Clin Pharmacokinet. 2010:49:71-87.

2. Roberts JA, Lipman J. Pharmacokinetic issues for antibiotics in the critically ill patients. Crit Care Med. 2009;37:840-51.

3. Alobaid AS, Hites M, Lipman J, Taccone FS, Roberts JA. Effect of obesity on the pharmacokinetics of antimicrobials in critically ill patients: A structured review. Int J Antimicrob Agents. 2016;47:259-68.

4. Grace E. Altered vancomycin pharmacokinetics in obese and morbidly obese patients: what we have learned over the past 30 years. J Antimicrob Chemother. 2012;67:1305-10

5. Kumar A, Roberts D, Wood KE, Light B, Parrillo JE, Sharma S, et al. Duration of hypotension before initiation of effective antimicrobial therapy is the 
critical determinant of survival in human septic shock. Crit Care Med. 2006;34:1589-96.

6. Adane ED, Herald M, Koura F. Pharmacokinetics of vancomycin in extremely obese patients with suspected or confirmed staphylococcus aureus infections. Pharmacotherapy. 2015;35:127-39.

7. Blouin RA, Bauer LA, Miller DD, Record KE, Griffen WO. Vancomycin pharmacokinetics in normal and morbidly obese subjects. Antimicrob Agents Chemother. 1982;4:575-80.

8. Bauer LA, Black DJ, Lill JS. Vancomycin dosing in morbidly obese patients. Eur J Clin Pharmacol. 1998:54:621-5.

9. Leong JV, Boro MS, Winter ME. Determining vancomycin clearance in an overweight and obese population. Am J Health-Syst Pharm. 2011;68:599-603.

10. Richardson J, Sheetz M, O'Donnell EP. The association of elevated trough serum vancomycin concentrations with obesity. J Infect Chemother. 2015:21:507-11.

11. Wysocki M, Delatour F, Faurisson F, Rauss A, Pean Y, Misset B, et al. Continuous versus intermittent infusion of vancomycin in severe Staphylococcal infections: prospective multicenter randomized study. Antimicrob Agents Chemother. 2001;45:2460-7.

12. Zelenitsky S, Rubinstein E, Ariano R, lacovides H, Dodek P, Mirzanejad Y, et al. Vancomycin pharmacodybamics and survival in patients with methicillin-resistance Staphylococcus aureus-associated septic shock. Int J Antimicrob Agents. 2013;41:255-60.

13. Cataldo MA, Tacconelli E, Grilli E, Pea F, Petrosillo N. Continuous versus intermittent infusion of vancomycin for the treatment of Gram-positive infections: systematic review and meta-analysis. J Antimicrob Chemother. 2012;67:17-24

14. Hanrahan T, Whitehouse T, Lipman J, Roberts JA. Vancomycin- associated nephrotoxicity: A meta-analysis of administration by continuous versus intermittent infusion. Int J Antimicrob Agents. 2015;46:249-53.

15. Vance-Bryan K, Guay DR, Gilliland SS, Rodvold KA, Rotschafer JC. Effect of obesity on vancomycin pharmacokinetic parameters as determined by using a Bayesian forecasting technique. Antimicrob Agents Chemother. 1993;37:436-40.

16. Alexander JK, Dennis EW, Smith WG, Amad KH, Duncan WC, Austin RC Blood volume, cardiac output, and distribution of systemic blood flow in extreme obesity. Cardiovasc Res Cent Bull 1962-63:1:39-44

17. Naeye RL, Roode P. The size and numbers of cells in visceral organs in human obesity. Am J Clin Pathol. 1970;54:251-3.

18. Rybak M, Lomaestro B, Rotschafer JC, Moellering Jr RC, Craig WA, Billeter M, et al. Vancomycin therapeutic guidelines: a sumarry of consensus recommendations from the infectious disease Society of America, the American Society of Health-System Pharmacists, and the Society of Infectious Diseases Pharmacists. Clin Infect Dis. 2009:49:325-37.

19. Baptista JP, Udy AA, Sousa E, Pimentel J, Wang L, Roberts JA, et al. A comparison of estimates of glomerular filtration in critically ill patients with augmented renal clearance. Crit Care. 2011;15:R139.

20. Baptista JP, Neves M, Rodrigues L, Teixeira L, Pinho J, Pimentel J, et al. Accuracy of the estimation of glomerular filtration rate within a population of critically ill patients. J Nephrol. 2014;27:403-10.

\section{Submit your next manuscript to BioMed Central and we will help you at every step:}

- We accept pre-submission inquiries

- Our selector tool helps you to find the most relevant journal

- We provide round the clock customer support

- Convenient online submission

- Thorough peer review

- Inclusion in PubMed and all major indexing services

- Maximum visibility for your research

Submit your manuscript at www.biomedcentral.com/submit
Biomed Central 